\title{
Climate sensitivity, agricultural productivity and the social cost of carbon in FUND
}

\author{
Kevin D. Dayaratna ${ }^{1} \cdot$ Ross McKitrick $^{2}$ (ID $\cdot$ Patrick J. Michaels ${ }^{3}$
}

Received: 17 June 2019 / Accepted: 6 January 2020 / Published online: 18 January 2020

(c) The Author(s) 2020

\begin{abstract}
We explore the implications of recent empirical findings about $\mathrm{CO}_{2}$ fertilization and climate sensitivity on the social cost of carbon (SCC) in the FUND model. New compilations of satellite and experimental evidence suggest larger agricultural productivity gains due to $\mathrm{CO}_{2}$ growth are being experienced than are reflected in FUND parameterization. We also discuss recent studies applying empirical constraints to the probability distribution of equilibrium climate sensitivity and we argue that previous Monte Carlo analyses in IAMs have not adequately reflected the findings of this literature. Updating the distributions of these parameters under varying discount rates is influential on SCC estimates. The lower bound of the social cost of carbon is likely negative and the upper bound is much lower than previously claimed, at least through the mid-twenty-first century. Also the choice of discount rate becomes much less important under the updated parameter distributions.
\end{abstract}

Keywords Agriculture $\cdot$ Climate sensitivity $\cdot \mathrm{CO}_{2}$ fertilization $\cdot$ Integrated assessment modeling $\cdot$ Social cost of carbon

\section{Introduction}

The marginal social cost of carbon dioxide emissions, usually shortened to the social cost of carbon (SCC), is typically derived using integrated assessment models (IAMs). While over 20 global-scale IAMs have been developed, three are specifically tailored to aggregate benefit-cost analysis and thus are most widely used in SCC estimation (Weyant 2017). These are called Dynamic Integrated ClimateEconomy (DICE, Nordhaus 1993), Framework for Uncertainty, Negotiation, and

Ross McKitrick

ross.mckitrick@uoguelph.ca

1 Heritage Foundation, Washington, DC, USA

2 Department of Economics and Finance, University of Guelph, Guelph, ON, Canada

3 Competitive Enterprise Institute, Washington, DC, USA 
Distribution (FUND, Tol 1997; Anthoff and Tol 2013) and Policy Analysis of the Greenhouse Effect (PAGE, Hope 2006). Modified versions of these three models were used by the US Interagency Working Group (IWG 2010, 2013) for regulatory SCC estimates that have been particularly influential on climate and energy regulations in the US and elsewhere.

While sharing many similarities, these IAMs also have some key differences. FUND, for instance, allows the agricultural sector in some regions to benefit from increased atmospheric carbon dioxide fertilization, while the others set such benefits to zero. PAGE incorporates the possibility of catastrophic damages due to abrupt and extreme "tipping point" events ${ }^{1}$ in the form of a long upper tail of costs at positive probabilities that the other models assume to be zero. These differences imply SCC estimates with a predictable ranking, from lowest to highest: FUND, DICE and PAGE.

Common to all models is the fact that, because of the long time horizons of the computations (over 200 years), the choice of discount rate is very influential on the results (Anthoff and Tol 2013). The assumed structure of the damage function is also critical (Marten 2011), as is the choice of equilibrium climate sensitivity (ECS), which represents the long-term temperature change from doubling atmospheric $\mathrm{CO}_{2}$, after allowing sufficient time for the deep ocean to respond to surface warming. Choices of these parameters dominate SCC estimates (Webster et al 2008; Wouter et al. 2012). ${ }^{2}$ Anthoff and Tol (2013) further report that agricultural productivity and air conditioning energy demand are critical parameterizations for determining the SCC in FUND.

Monte Carlo analysis of plausible ranges of a small number of parameters has yielded such a wide dispersion of SCC results that IAMs have been criticized as arbitrary and potentially meaningless (Tol 2017; Pindyck 2013). But as Weyant (2017) points out, the models are still useful when understood as "if-then" statements. Rather than seeking a single canonical SCC estimate, the models allow traceability from assumptions to implications. Thus increased precision of SCC estimates will not primarily come from increasing the complexity of IAMs themselves but from debating structural assumptions and reducing the uncertainty over key parameter values (Gillingham et al. 2018). Consequently, there is a need to bridge efficiently between empirical research on climate-related parameters and Monte Carlo IAM analysis.

Here we focus on agricultural productivity and climate sensitivity. We do not explore the role of future extreme or abrupt events because of the lack of empirical basis for Monte Carlo simulations. The distributions in question are influential on simulated damages but difficult to specify with sufficient precision. Weyant (2017) notes that exclusion of just the top $1 \%$ of the damage estimates in the PAGE model

\footnotetext{
${ }^{1}$ Such outcomes are characterized by abrupt changes in planetary-scale systems such as the Atlantic meridional overturning circulation, which moderates the climate of northern Europe, and melting of the Greenland ice cap.

${ }^{2}$ Another critical parameter is the degree of risk aversion, but we subsume that here in the selection of the discount rate.
} 
causes the standard deviation of its SCC estimates to fall from $\$ 266$ per ton to $\$ 56$ per ton, but there is no observational basis for parameterizing either the probabilities of the events or the economic costs. In lieu of an observed distribution PAGE makes use of expert elicitations, the value of which are debatable, while FUND and DICE have been used to examine extreme events under special parameterizations (Link and Tol 2011; Nicholls et al. 2008; Cai and Lontzek 2019). For our purposes herein, we simply note that allowing for the possibility of low-probability catastrophic events will imply a higher SCC estimate, with the amounts entirely dependent on the scenario and the assumed probabilities.

Because of the structural differences, it is not valid simply to average across FUND, DICE and PAGE in the hope of obtaining an unbiased mean. It is also factually incorrect to set $\mathrm{CO}_{2}$ fertilization to zero as is done in DICE and PAGE. We confine our analysis to the FUND model (version 3.8.1 as used by the US IWG 2013), since it has the appropriate structure to allow $\mathrm{CO}_{2}$ fertilization benefits, and we examine changes in the SCC based on new parameter distributions. We review research published long after the original calibration of FUND regarding agricultural productivity changes under higher $\mathrm{CO}_{2}$ levels to update the Monte Carlo simulation range.

We also consider uncertainty regarding climate sensitivity, as did the IWG (2010,2013), Dayaratna et al. (2017), and Gillingham et al. (2018). While IAMs have been run under a customary ECS range derived from climate models, little attention has been paid to the many empirically based estimates published in the last half decade which have tended to be lower than the model-based range. Dayaratna et al. (2017) show that use of an empirically constrained ECS parameter distribution substantially reduces the SCC estimate from DICE and FUND, which we also find herein.

We will examine results under a range of discount rates from 2.5 to $7.0 \%$. The high end rate is above that typically used in long-term climate studies, but remains part of US Office of Management and Budget Guidelines so is commonly used for cost-benefit analysis (US Office of Management and Budget 2003). We primarily focus our discussion on the results under a 3.0\% discount rate. Under the modelbased ECS range, the choice of discount rate matters acutely, with a change from 2.5 to $5.0 \%$ sufficient to reduce the SCC by about $90 \%$ through 2050 . However, under an empirically based ECS, the choice of discount rate ceases to matter. Such distributions still induce proportionately large changes in SCC and also causes sign changes, but the absolute changes are very small because the SCC itself collapses to a very small amount.

\section{Uncertainties in agriculture and climate sensitivity}

\subsection{Agricultural productivity change}

It has been known for decades that increasing the atmospheric concentration of carbon dioxide enhances plant growth (Idso and Idso 1994; Cuniff et al. 2008) both by raising the rate of net photosynthesis and increasing water use efficiency within the plant. For numerous crop types around the world, $\mathrm{CO}_{2}$ fertilization more than offsets 
negative effects of climate change on crop water productivity, with some of the largest gains likely in arid and tropical regions (Derying et al. 2016). An additional benefit of climate warming arises from lengthening the growing season-the time between the last killing frost of the spring and the first one in the fall. Studies of US maize that take into account farmer adaptation to changing growing conditions confirm the potential for net yield gains under climate change (Butler et al. 2018).

FUND attempts to capture these changes in a simple form. The FUND model estimates agricultural output as a fraction of total output, where the fraction declines over time at a rate consistent with historical data. Specifically, the output share of agriculture at year $t$ is the product of the 1990 agricultural output share and $\left(y_{1990, r} / y_{t, r}\right)^{0.31}$ where $y_{t, r}$ is GDP per capita in year $t$ for region $r$. From 1990 to 2050 , this expression declined steadily from 1.0 to about 0.7 , so if $5.0 \%$ of an economy's output is agricultural as of 1990, by 2050 that would decline to about $3.5 \%$. This equation determines the potential welfare associated with regional agricultural output, and actual welfare is then determined by a parameterized function that depends on the temperature level, speed of climate change, and atmospheric $\mathrm{CO}_{2}$. Changes in each of these affect welfare by changing regional agricultural yields, which in turn affect prices and trade patterns. Consequently, the function parameters vary among regions. A reduction in the yield of a particular crop, for example, will tend to harm import-dependent regions but might benefit exporting regions.

The temperature-level effect is represented by a quadratic equation with an implicit peak that a region may either be approaching or diverging from as it warms. The temperature change effect penalizes productivity in intervals when temperature changes rapidly from one year to the next. We take the parameter distributions associated with these effects as given.

The $\mathrm{CO}_{2}$ fertilization effect $A_{\mathrm{r}}$ for region $r$ is determined by a logarithmic function:

$$
A_{\mathrm{r}}=\gamma_{\mathrm{r}} \ln \left(\frac{\mathrm{CO}_{2}(t)}{275}\right) \text {, }
$$

where $\mathrm{CO}_{2}(t)$ is the current atmospheric $\mathrm{CO}_{2}$ concentration with 275 parts per million assumed to be the preindustrial level and $\gamma_{\mathrm{r}}$ is a region-specific constant derived by calibration to the results of a number of studies done using computable general equilibrium models, chiefly Tsigas et al. (1997) who separated out the $\mathrm{CO}_{2}$ fertilization effect. An earlier global general equilibrium study, Kane et al. (1992), reported potential yield decline due to temperature increase based on simulations that did not include $\mathrm{CO}_{2}$ fertilization, but added that based on the limited amount of information then available, doubling the amount of $\mathrm{CO}_{2}$ in the atmosphere could increase yield by about $15 \%$. By the time of Tsigas et al. (1997) more information was available and they incorporated global yield gains averaging between 20 and $30 \%$ for $\mathrm{CO}_{2}$ doubling. The effects were large enough effectively to negate the losses from moderate climate changes and generate some regional net gains. The authors thus emphasized in their conclusions the importance of including $\mathrm{CO}_{2}$ fertilization effects in future studies so as not to overstate the net damages of climate change in agriculture. 
The parameterizations in FUND are consistent with this early evidence. Of particular note, while the categories wheat and other crops experience net gains from the combination of warming and $\mathrm{CO}_{2}$ fertilization, rice does not, based on the limited studies then available that suggested $\mathrm{CO}_{2}$ fertilization would insufficiently offset damages due to warming. Because of the importance of rice in China and Asia, this assumption is influential on overall climate damages (Tsigas et al. 1997, Table 11.2).

Three forms of evidence gained since then indicates that the $\mathrm{CO}_{2}$ fertilization effects in FUND may be too low. First, rice yields have been shown to exhibit strong positive responses to enhanced ambient $\mathrm{CO}_{2}$ levels. Kimball (2016) surveyed results from free-air $\mathrm{CO}_{2}$ enrichment (FACE) experiments, and drew particular attention to the large yield responses (about 34\%) of hybrid rice in $\mathrm{CO}_{2}$ doubling experiments, describing these as "the most exciting and important advances" in the field. FACE experiments in both Japan and China showed that available cultivars respond very favorably to elevated ambient $\mathrm{CO}_{2}$. Furthermore, Challinor et al (2014), Zhu et al. (2015) and Wu et al. (2018) all report evidence that hybrid rice varietals exist that are more heat-tolerant and therefore able to take advantage of $\mathrm{CO}_{2}$ enrichment even under warming conditions (2013). Collectively, this research thus indicates that the rice parameterization in FUND is overly pessimistic.

Second, satellite-based studies have yielded compelling evidence of stronger general growth effects than were anticipated in the 1990s. Zhu et al (2016) published a comprehensive study on greening and human activity from 1982 to 2009. The ratio of land areas that became greener, as opposed to browner, was approximately 9 to 1. The increase in atmospheric $\mathrm{CO}_{2}$ was just under $15 \%$ over the interval but was found to be responsible for approximately $70 \%$ of the observed greening, followed by the deposition of airborne nitrogen compounds (9\%) from the combustion of coal and deflation of nitrate-containing agricultural fertilizers, lengthening growing seasons $(8 \%)$ and land cover changes (4\%), mainly reforestation of regions such as southeastern North America.

Zhu et al. used satellite-sensed leaf area index (LAI), which does not directly translate into grain yields - rather it is a measure of direct fertilization and the production of dry matter. However, for grassland, the most common agricultural land use, LAI in fact does relate directly to yield since grassland vegetation is consumed by grazing animals, and it is harvested for hay to feed livestock in the nongrowing season as well as to feed livestock removed from pasture. Also, in a new analysis of satellite LAI data, Gao et al. (2018) reported that agriculture-related trends were more than double those of natural vegetation, indicating that trends in LAI are likely indicators of increased agricultural productivity.

Munier et al. (2018) likewise found a remarkable increase in the yield of grasslands. In a 17-year (1999-2015) analysis of satellite-sensed LAI, during which time the atmospheric $\mathrm{CO}_{2}$ level rose by about $10 \%$, there was an average LAI increase of $85 \%$. A full $31 \%$ of earth's continental land outside of Antarctica is covered by grassland, the largest of the three agricultural land types they classified. Also, for summer crops, such as maize (corn) and soybeans, greening increased by an average of $52 \%$, while for winter crops, whose area is relatively small compared to those for summer, the increase was $31 \%$. If $70 \%$ of the yield gain is attributable to increased $\mathrm{CO}_{2}$, the results from $\mathrm{Zhu}$ et al (2016) imply gains of $60 \%, 36 \%$ and $22 \%$ over the 


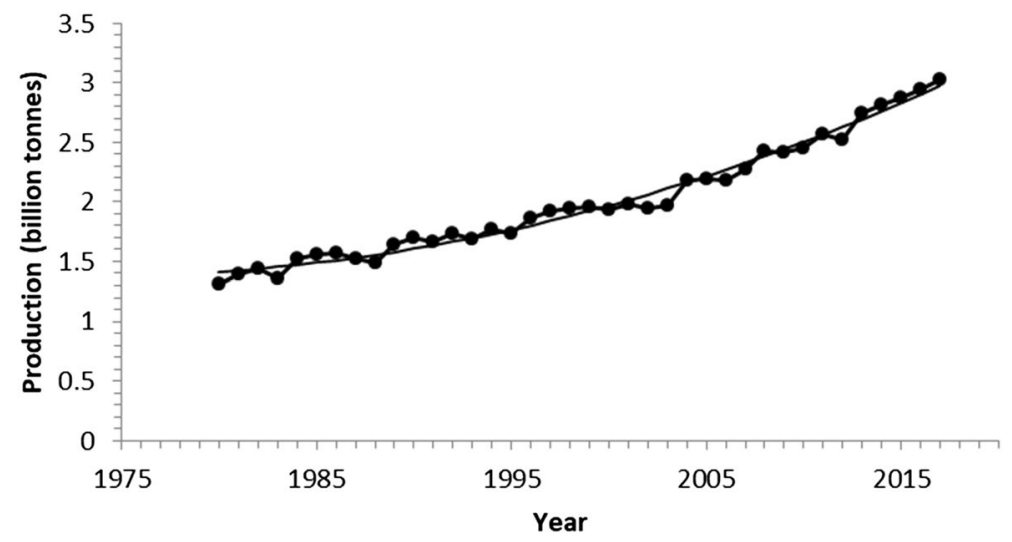

Fig. 1 Global crop production shown as sum of maize, rice, soybean and wheat grown during 19802017. Source: authors' calculation using data from https://www.fao.org/faostat/en/\#data/QC/visualize. Fitted line is a quadratic trend

17-year period for, respectively, grasslands, summer crops and winter crops, associated with only a $10 \%$ increase in $\mathrm{CO}_{2}$, compared to parameterized yield gains in the range of $20-30 \%$ for $\mathrm{CO}_{2}$ doubling in FUND.

Third, there has been an extensive amount of research since Tsingas et al. (1997) on adaptive agricultural practices under simultaneous warming and $\mathrm{CO}_{2}$ enrichment. Challinor et al. (2014) surveyed a large number of studies that examined responses to combinations of increased temperature, $\mathrm{CO}_{2}$ and precipitation, with and without adaptation. In their metanalysis, average yield gains increased $0.06 \%$ per ppm increase in $\mathrm{CO}_{2}$ and $0.5 \%$ per percentage point increase in precipitation, and adaptation added a further $7.2 \%$ yield gain, but warming decreased it by $4.9 \%$ per ${ }^{\circ} \mathrm{C}$. In FUND, $3{ }^{\circ} \mathrm{C}$ warming negates the yield gains due to $\mathrm{CO}_{2}$ enrichment, but this is not what the Challinor et al. results imply. Suppose that over the next 100 years, $\mathrm{CO}_{2}$ doubles from 400 to $800 \mathrm{pm}$ while temperatures rise by $3{ }^{\circ} \mathrm{C}$ and precipitation increases on average by $2 \%$, Challinor et al.'s regression coefficients would imply an average yield increase of $2.2 \%$ in the tropics without adaptation versus $9.3 \%$ with; and $5.0 \%$ outside the tropics without adaptation versus $12.1 \%$ with, indicating the productivity increase in FUND is likely too small.

Figure 1 provides further evidence based on the recent historical record. It shows total global output of maize, rice, soybeans and wheat per year from 1980 to 2017. Over this interval, the global average land surface was estimated to have warmed by $1.0{ }^{\circ} \mathrm{C},{ }^{3}$ the $\mathrm{CO}_{2}$ concentration rose by $68 \mathrm{ppm}^{4}$ and crop output doubled. Hence, the record since 1980 provides prima facie evidence that the combined effects of warming, $\mathrm{CO}_{2}$ fertilization and adaptation can have positive net growth results at the

\footnotetext{
${ }^{3}$ According to the CRUTEMv4 global land record at https://crudata.uea.ac.uk/cru/data/temperature/ CRUTEM4-gl.dat.

${ }^{4}$ See https://www.esrl.noaa.gov/gmd/ccgg/trends/data.html.
} 
global level, and the meta-analysis results indicate the direction of this balance is likely to persist.

In light of these issues, we examine the effects of increasing the $\gamma_{\mathrm{r}}$ parameters in FUND by $15 \%$ and $30 \%$, namely multiplying them by 1.15 and 1.30 . These changes are conservative in view of the evidence on $\mathrm{CO}_{2}$-driven growth enhancement; however, they provide guidance on the sensitivity of the SCC to the emergent information on agricultural productivity.

\subsection{Climate sensitivity}

ECS is the most basic measure within an IAM of $\mathrm{CO}_{2}$ impacts on climate. Secondary impacts, such as sea-level rise, changes in storm intensity, depth and frequency of droughts and floods, etc., all depend on a reliable ECS.

The mean ECS of the climate models used in the most recent Assessment Report of the United Nations' Intergovernmental Panel on Climate Change (IPCC 2013) was $3.2{ }^{\circ} \mathrm{C}$ by the IPCC and $3.4{ }^{\circ} \mathrm{C}$ in the peer-reviewed literature describing those models (Andrews et al. 2012). The IWG applied Monte Carlo analysis to the ECS parameter using a distribution published in Roe and Baker (2007), based on climate models, which has a median value of $3.0{ }^{\circ} \mathrm{C}$, a $90 \%$ confidence interval range from 1.91 to $5.86{ }^{\circ} \mathrm{C}$, and is truncated at an upper limit of 10 degrees Celsius (IWG 2010). Roe and Bauman (2013) criticized the application of the Roe and Baker (2007) distribution in IAMs, because the higher climate sensitivities imply time spans to equilibrium which are inconsistent with the assumed speed of adjustment (via ocean heat uptake efficiency) in IAMs. The time to equilibrium in simple climate models goes up with the square of ECS, and the fat upper tail of ECS values implies such long adjustment times that realization of such warming takes over a 1000 years (Roe and Bauman 2013, p. 653). IAMs apply these high-sensitivity estimates on much shorter time scales, which Roe and Bauman argue involves physically impossible outcomes.

More fundamentally, the climate model-based ECS distributions have been challenged within the climate literature as potentially being arbitrary. There are numerous tunable parameters in climate models (Hourdin et al. 2017), and a range of sensitivity values can be made to fit the historical record equally well as long as tunings that increase climate sensitivity are accompanied by compensating adjustments elsewhere, which appears to be the case (Kiehl 2007).

A valid ECS estimate for use in IAMs must therefore be based on empirical constraints. Use of climate model-based metrics to construct Bayesian models may not get around the problem of arbitrariness. Lewis (2013) criticized the use of informative priors in Bayesian ECS derivations similar to that used in Olsen et al. (2012), in which likelihoods are derived from diagnostics of model-observational discrepancies, which are in turn functions of the model parameters. Because of parameter interdependence in the models, the diagnostics do not strongly constrain the ECS distribution and the posterior density is typically very close to the subjective prior. As an example, he reproduced an earlier Bayesian ECS estimation that had yielded a distribution similar to that in Roe and Baker. He found that under an informative prior, large sections of the posterior ECS distribution were unresponsive to the 
observations. Application of an objective Bayesian method on the same data set, however, yielded a lower and more tightly constrained distribution with a mode of $1.6{ }^{\circ} \mathrm{C}$ and a $90 \%$ credible interval of $1.2-2.2^{\circ} \mathrm{C}$.

Lewis (2013) noted that this mode was identical to that found in two contemporaneous empirical studies (Aldrin et al. 2012; Ring et al. 2012) that had estimated relatively simple energy balance models on observational data. This latter approach has subsequently been widely applied yielding modal ECS values consistently below $2.0^{\circ} \mathrm{C}$ and much narrower confidence or credible intervals (Otto et al. 2013; Masters 2014; Lewis and Curry 2015; Skeie et al 2014 Lewis and Curry 2018). Of particular interest is the distribution in Lewis and Curry (2018) since it is conditioned on a joint estimation with ocean heat uptake efficiency, uses up-to-date estimates of aerosol forcing from the IPCC and explicitly addresses concerns about spatial variation in effective forcing and other potential deficiencies of empirical energy balance model methods. Based on the post-1850 Hadley Centre surface temperature data set their best estimate of ECS is 1.50 with a $5-95 \%$ range of $1.05-2.45^{\circ} \mathrm{C} .{ }^{5} \mathrm{By}$ conditioning the estimate on ocean heat uptake efficiency the method yields an ECS distribution consistent with the main observed constraint on time to equilibrium, addressing the concern in Roe and Baumann (2013).

Beyond energy balance models, there are other even more strictly empirical methods. One approach is to estimate transient climate sensitivity (TCS, the estimated warming from doubling greenhouse gas levels over a 70-year span without allowing the oceans fully to adjust) then scaling it up to an ECS estimate based on an estimated ratio of the two. Christy and McNider (2017) used satellite bulk atmospheric temperature data from $1979-2016$ and estimated a TCR of $1.1 \pm 0.26^{\circ} \mathrm{C}$ which is similar to the Lewis and Curry (2018) estimate of $1.2{ }^{\circ} \mathrm{C}\left(5-95 \% 0.9-1.7{ }^{\circ} \mathrm{C}\right)$. Using the estimated ECS/TCR ratio of 1.3 in Lewis and Curry (2018) implies a corresponding ECS mode of $1.4{ }^{\circ} \mathrm{C}$ in Christy and McNider (2017).

These are very different ECS ranges from the ones used by the IWG and unsurprisingly they yield much lower SCC estimates. We will review arguments in the final section why the lower estimates are relevant for IAM studies.

In our implementation herein, the Christy and McNider (2017) and Lewis and Curry (2018) distributions were sampled using inverse transform sampling. We had the full ECS distribution from Lewis and Curry (2018) from which to sample. For the Christy and McNider (2017) distribution, we fit a generalized gamma distribution to 5th, 50th, and 95th percentiles of the associated distributions via the method of least squares. Figure 2 shows plots of these probability density functions, as well as the Roe-Baker (2007) distribution used in this study.

\subsection{Discount rate}

The long-running debate about appropriate discount rates for climate change policy analysis will not be reviewed here. Considerations of uncertainty and the

\footnotetext{
${ }^{5}$ Use of an infilled data set to expand coverage over the Arctic raises the mode to $1.66{ }^{\circ} \mathrm{C}$ and the upper bound of the $5-95 \%$ range to $2.7^{\circ} \mathrm{C}$.
} 


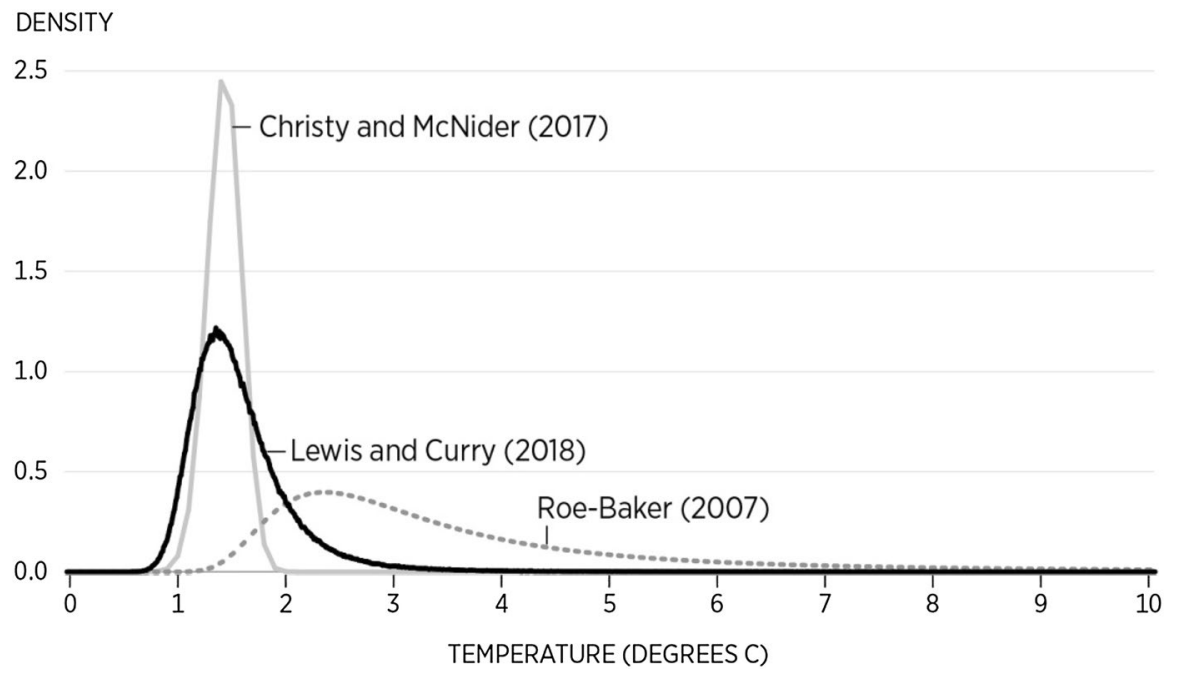

Fig. 2 Probability density functions of equilibrium climate sensitivity distributions used to estimate the social cost of carbon

ethical argument against time preference lead to a preference for a low discount rate, whereas viewing the discount rate as an opportunity cost of capital leads to a preference for a higher discount rate. We will present results using 2.5\%, 3\%, 5\% and 7\%.

\subsection{Economic intuition}

Simulations of the economic impacts of $\mathrm{CO}_{2}$ emissions differ from those of conventional pollution in a few important ways, which taken together give rise to the possibility that the SCC can be negative as well as positive. First, whereas air contaminants like particulates and nitrogen oxides are directly injurious to human health, $\mathrm{CO}_{2}$ is not. Because exhaled breath has a very high $\mathrm{CO}_{2}$ concentration, when people travel in cars or spend time in crowded buildings (such as office towers) they routinely experience $\mathrm{CO}_{2}$ exposure at levels far higher than outdoors, without noticeable effects. Second, $\mathrm{CO}_{2}$ is a principal food source for plants, and if the only environmental effect of $\mathrm{CO}_{2}$ were its aerial fertilization of plant life then emissions would almost certainly be a net benefit. But (third) its other main environmental effect is its infrared absorption property, which gives rise to projected atmospheric warming as outdoor $\mathrm{CO}_{2}$ levels increase. Here again the effects on plants, animals and people are complex and may involve gains as well as losses. A longer growing season and less harsh winters may be a net benefit in some regions, whereas more drought and heat stress would reduce agricultural productivity. Also, if changing temperatures increase (decrease) the risk of extreme weather events, economic damages will in consequence increase (decrease).

IAM simulations attempt to represent these offsetting factors to give an idea of circumstances under which the net effects would be positive or negative. If the overall economic effects of increased $\mathrm{CO}_{2}$ are positive, this implies a negative SCC, and 
Table 1 Mean social cost of carbon in FUND model using Roe-Baker (2007) ECS distribution and original agricultural $\mathrm{CO}_{2}$ fertilization parameter $(\mathrm{Ag}+0 \%$ column $)$, then with $\mathrm{CO}_{2}$ fertilization parameter increased by $15 \%$ and $30 \%(\mathrm{Ag}+15 \%, \mathrm{Ag}+30 \%$, respectively)

\begin{tabular}{llll}
\hline Year & \multicolumn{2}{l}{ Roe-Baker distribution, 3.0\% discount rate } \\
\cline { 2 - 4 } & $\mathrm{Ag}+0 \%$ & $\mathrm{Ag}+15 \%$ & $\mathrm{Ag}+30 \%$ \\
\hline 2020 & $\$ 19.33$ & $\$ 18.14(-6 \%)$ & $\$ 14.75(-24 \%)$ \\
2030 & $\$ 21.78$ & $\$ 20.79(-5 \%)$ & $\$ 16.74(-23 \%)$ \\
2040 & $\$ 24.36$ & $\$ 23.53(-3 \%)$ & $\$ 18.36(-25 \%)$ \\
2050 & $\$ 27.06$ & $\$ 26.30(-3 \%)$ & $\$ 20.38(-25 \%)$ \\
\hline
\end{tabular}

Percentage changes in brackets are relative to the base case in column 1

vice versa. By assuming away $\mathrm{CO}_{2}$ fertilization effects, DICE and PAGE leave out a potential beneficial side effect and their resulting SCC estimates are, as a consequence, higher. Since DICE and PAGE assume $\mathrm{CO}_{2}$ only causes damages their SCC estimates can never go negative. The damage function in FUND is not a single function in temperature and sea-level rise (as is the case with DICE), instead it is an accumulation of sector- and region-specific effects that depend on temperature and other climatic parameters. A fitted line through global net economic damages from warming has, in the case of FUND, a segment that goes below zero for low levels of warming, implying a negative SCC. Some previous analyses have shown this outcome (see IWG 2010, Fig. 1a, also see Dayaratna et al. 2017). The fact that DICE and PAGE cannot generate a negative SCC does not make FUND an "outlier", the restriction is imposed on DICE and PAGE by assumption. If they allowed for $\mathrm{CO}_{2}$ fertilization effects comparable to those in FUND, then they would likely generate negative SCC estimates over moderate warming intervals as well.

\section{Results}

Table 1 reports on results using the Roe and Baker (2007) distribution (corresponding to the IWG 2013) allowing for a $15 \%$ and $30 \%$ increase in the agricultural productivity parameters. We only show the $3.0 \%$ discount rate case since the relative changes are similar for the other discount rates. Decadally from 2020 to 2050, the mean SCC grows from $\$ 19.33$ to $\$ 27.06$ per ton of $\mathrm{CO}_{2}$ under the base case. ${ }^{6} \mathrm{~A} 15 \%$ increase in $\gamma_{\mathrm{r}}$ reduces this estimate only modestly, becoming $\$ 18.14-\$ 26.30$ per ton, a change of $-6.2 \%$ in 2020 but only $-2.8 \%$ by 2050 . But a $30 \%$ productivity coefficient increase yields a proportionately larger effect, with the SCC ramp becoming $\$ 14.75-\$ 20.38$, a consistent reduction of about $24 \%$ compared to the base case values in all years. This percentage change indicates that the increased $\mathrm{CO}_{2}$ productivity component has a nonlinear impact on the SCC, though the gains do level out. In an unreported sensitivity analysis, we increased the $\gamma_{\mathrm{r}}$ parameters by $75 \%$, and the 2020-2050 SCC ramp became, respectively, \$10.72, \$12.76, \$15.04 and \$17.56,

\footnotetext{
${ }^{6}$ All SCC estimates herein are reported as US 2007 dollars per metric ton of $\mathrm{CO}_{2}$.
} 
Table 2 Mean social cost of carbon in FUND model at discount rates of $2.5 \%, 3 \%, 5 \%$ and $7 \%$, using Roe and Baker (2007) ECS distribution and Lewis and Curry (2018) ECS distribution ("LC18"), under the base case (second column), and with $15 \%$ and $30 \%$ increases in the $\mathrm{CO}_{2}$ fertilization parameters (LC18+15\%, LC18+30\%, respectively)

\begin{tabular}{|c|c|c|c|c|}
\hline & Roe-Baker & LC18 & $\mathrm{LC} 18+15 \%$ & $\mathrm{LC} 18+30 \%$ \\
\hline \multicolumn{5}{|l|}{$2.5 \%$} \\
\hline 2020 & $\$ 32.90$ & $\$ 3.78 / 0.46$ & $\$ 0.62 / 0.53$ & $-\$ 1.53 / 0.59$ \\
\hline 2030 & $\$ 36.16$ & $\$ 4.69 / 0.44$ & $\$ 1.25 / 0.51$ & $-\$ 1.02 / 0.57$ \\
\hline 2040 & $\$ 39.53$ & $\$ 5.76 / 0.42$ & $\$ 2.03 / 0.48$ & $-\$ 0.33 / 0.54$ \\
\hline 2050 & $\$ 42.98$ & $\$ 6.98 / 0.39$ & $\$ 2.96 / 0.46$ & $-\$ 0.55 / 0.51$ \\
\hline \multicolumn{5}{|l|}{$3.0 \%$} \\
\hline 2020 & $\$ 19.33$ & $\$ 1.61 / 0.49$ & $-\$ 0.82 / 0.57$ & $-\$ 2.74 / 0.63$ \\
\hline 2030 & $\$ 21.78$ & $\$ 2.32 / 0.47$ & $-\$ 0.35 / 0.54$ & $-\$ 2.39 / 0.61$ \\
\hline 2040 & $\$ 24.36$ & $\$ 3.18 / 0.44$ & $\$ 0.28 / 0.51$ & $-\$ 1.85 / 0.57$ \\
\hline 2050 & $\$ 27.06$ & $\$ 4.21 / 0.42$ & $\$ 1.08 / 0.48$ & $-\$ 1.12 / 0.54$ \\
\hline \multicolumn{5}{|l|}{$5.0 \%$} \\
\hline 2020 & $\$ 2.54$ & $-\$ 1.02 / 0.62$ & $-\$ 2.25 / 0.71$ & $-\$ 3.41 / 0.78$ \\
\hline 2030 & $\$ 3.31$ & $-\$ 0.77 / 0.58$ & $-\$ 2.14 / 0.67$ & $-\$ 3.41 / 0.74$ \\
\hline 2040 & $\$ 4.21$ & $-\$ 0.39 / 0.54$ & $-\$ 1.89 / 0.63$ & $-\$ 3.24 / 0.70$ \\
\hline 2050 & $\$ 5.25$ & $\$ 0.15 / 0.49$ & $-\$ 1.47 / 0.58$ & $-\$ 2.87 / 0.65$ \\
\hline \multicolumn{5}{|l|}{$7.0 \%$} \\
\hline 2020 & $-\$ 0.37$ & $-\$ 1.25 / 0.71$ & $-\$ 2.06 / 0.80$ & $-\$ 2.84 / 0.85$ \\
\hline 2030 & $-\$ 0.13$ & $-\$ 1.18 / 0.67$ & $-\$ 2.08 / 0.76$ & $-\$ 2.94 / 0.82$ \\
\hline 2040 & $\$ 0.19$ & $-\$ 0.98 / 0.62$ & $-\$ 1.98 / 0.71$ & $-\$ 2.91 / 0.77$ \\
\hline 2050 & $\$ 0.63$ & $-\$ 0.66 / 0.56$ & $-\$ 1.74 / 0.65$ & $-\$ 2.71 / 0.72$ \\
\hline
\end{tabular}

In the last three columns the entry shows the SCC estimate and the associated probability of a negative SCC

a drop of $45 \%$ as of 2020 shrinking to $35 \%$ as of 2050 relative to the base case. Consequently, we conclude that updating the agricultural effects of $\mathrm{CO}_{2}$ fertilization yields a modest but important change in the SCC estimates. If the productivity gains are only $15 \%$ higher the effect is relatively minor, but they apparently grow quickly thereafter and a $30 \%$ gain causes the SCC estimate to fall by nearly one quarter.

Table 2 shows the effect of changing to the Lewis and Curry (2018) ECS distribution (column labeled LC18), then introducing higher agricultural productivity parameters (columns labeled LC18 +15 and LC18 +30 , respectively). Results for discount rates of $2.5-7 \%$ are shown in different panels. As has also been illustrated in prior research (Dayaratna et al. 2017), it is clear that the ECS parameter choice is highly influential on the SCC estimates. Under a 3.0\% discount rate, changing to the LC18 case causes the mean SCC estimate to drop from $\$ 19.33$ in 2020 to only $\$ 1.61$. Adding $15 \%$ and $30 \%$ to the agricultural productivity coefficient drops this further to $-\$ 0.82$ and $-\$ 2.74$, respectively, implying that, after taking into account enhanced agricultural productivity and recent empirical evidence on climate sensitivity, $\mathrm{CO}_{2}$ is not a negative externality in FUND as of 2020. Even as far forward as 2050 , and even under a $2.5 \%$ discount rate, the SCC remains negative using the Lewis and Curry ECS estimate under a $30 \%$ gain in agricultural productivity. Figure 3 compares the results for the $2.5 \%$ discount rate case, clearly showing that the choice of ECS parameter is very influential even at a low discount rate. 


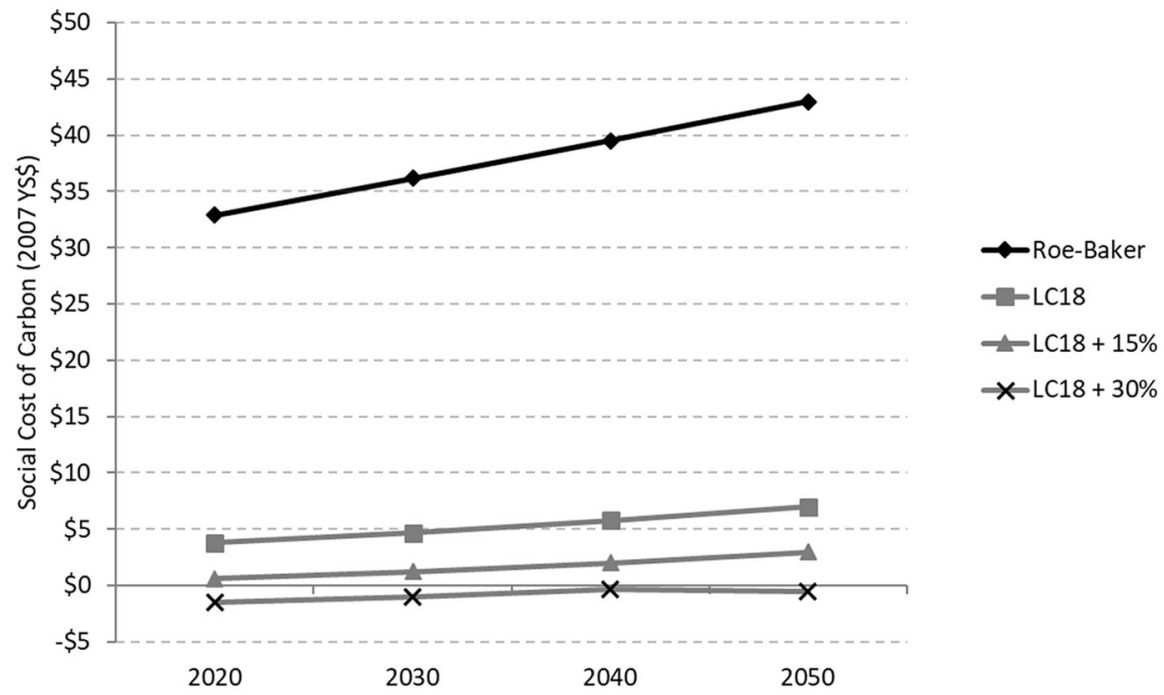

Fig. 3 Mean social cost of carbon in 2007 US\$ as computed by FUND between 2020 and 2050 using 2.5\% discount rate; and Roe and Baker (2007) ECS distribution (Roe-Baker); Lewis and Curry (2018) ECS distribution (LC18); LC18 and 15\% increase in $\mathrm{CO}_{2}$ fertilization parameter (LC18+15\%); LC18 and $30 \%$ increase in $\mathrm{CO}_{2}$ fertilization parameter $(\mathrm{LC} 18+30 \%)$

Table 3 Mean social cost of carbon in FUND model using Christy and McNider (2017) ECS distribution and original agricultural $\mathrm{CO}_{2}$ fertilization parameter $\left(\mathrm{Ag}+0 \%\right.$ column), then with $\mathrm{CO}_{2}$ fertilization parameter increased by $15 \%$ and $30 \%(\mathrm{Ag}+15 \%, \mathrm{Ag}+30 \%$, respectively)

\begin{tabular}{llll}
\hline Year & \multicolumn{4}{l}{ Christy-McNider distribution, 3.0\% discount rate } \\
\cline { 2 - 4 } & $\mathrm{Ag}+0 \%$ & $\mathrm{Ag}+15 \%$ & $\mathrm{Ag}+30 \%$ \\
\hline 2020 & $-\$ 1.34 / 0.58$ & $-\$ 3.50 / 0.66$ & $-\$ 5.73 / 0.72$ \\
2030 & $-\$ 0.95 / 0.55$ & $-\$ 3.29 / 0.63$ & $-\$ 5.70 / 0.69$ \\
2040 & $-\$ 0.40 / 0.52$ & $-\$ 2.90 / 0.60$ & $-\$ 5.48 / 0.66$ \\
2050 & $\$ 0.32 / 0.48$ & $-\$ 2.33 / 0.56$ & $-\$ 5.06 / 0.62$
\end{tabular}

Each entry shows the SCC estimate and the associated probability of a negative SCC

Associated with each entry in the last three columns of Table 2 is the probability of a negative SCC. The SCC shown is the mean of a distribution and the probability measures the fraction of the distribution lying below zero. Under the LC18 +15 case, even at a discount rate of $2.5 \%$ the probability of a negative SCC exceeds 0.45 out to 2050 . At a $5 \%$ discount rate and a $30 \%$ gain in agricultural productivity, there is at least a 0.65 probability that SCC is negative out to 2050 . If instead we use a $2.5 \%$ discount rate, the probability nonetheless remains over 0.5 .

It is also noteworthy that once the ECS distribution is changed to that in Lewis and Curry (2018), the SCC estimates are, whether positive or negative, very small. As a public policy matter, after downscaling these estimates by the marginal cost of public funds (Sandmo 1975), the model's implication would be that the optimal 
emission tax would be so small as to be practically equivalent to business as usual, or even negative.

Finally, in Table 3 we present the results for the $3 \%$ discount rate case using the ECS estimate derived from Christy and McNider (2017). It is notable that this ECS estimate is based on a different temperature data set than Lewis and Curry (2018), and focuses only on the last 40 years and on the lower troposphere where models project a somewhat stronger warming response than at the surface. The results are similar to those based on Lewis and Curry (2018) but are three or four dollars lower in each configuration.

\section{Discussion: IAMs as if-then statements}

IAMs cannot provide a single, canonical social cost of carbon. As Weyant (2017) notes, they are best thought of as elaborate "if-then" statements. Researchers must decide on their preferred premises, and the IAMs provide the implied SCC range. As shown herein, user judgment is unavoidable, and a researcher prescribing an SCC for policy purposes must be able to defend the "if" statements that give rise to it.

It is already well known that if the appropriate discount rate is $5 \%$ or higher, then the SCC will be relatively small compared to $2.5 \%$ or $3 \%$ cases. We do not propose to resolve herein the ethical arguments over time preference; instead, we note that once climate sensitivity is changed to an empirically constrained distribution, the choice of discount rate matters a lot less.

While some studies have considered ranges of ECS values, the IAM literature as a whole has been wedded to climate model-based distributions with modal values around $3{ }^{\circ} \mathrm{C}$ and thick upper tails extending above $6{ }^{\circ} \mathrm{C}$. However, there is now a substantial climatological literature showing that distributions with modal values below $2{ }^{\circ} \mathrm{C}$ and small upper tails match historical (post-1850) data better. The debate over which distribution best describes the real climate system must ultimately be resolved within the climatology literature, but economists need to be aware that it exists and the outcome has significant ramifications for SCC estimates. If ECS values like those estimated in Lewis and Curry (2018) turn out to be approximately correct, then the FUND model indicates that $\mathrm{CO}_{2}$ is for all practical purposes not a negative global externality through mid-century. Even if we consider possible catastrophic tipping points, the possibility of reaching such a threshold any time in the next 1000 years diminishes substantially.

IAM practitioners should therefore study the empirically constrained ECS estimates rather than relying exclusively on model-derived distributions. Kiehl (2007) noted the puzzle that climate models can differ in their implied ECS by a factor of 3 yet all fit the historical surface temperature record equally well. One of the compensating parameterizations emphasized by Lewis and Curry (2018) is aerosol cooling: a model with high ECS paired with strong aerosol cooling fits the surface trend as well as one with low ECS and weak aerosol cooling. The Lewis and Curry (2018) empirical ECS distribution is conditioned on the IPCC's updated estimates of observed historical aerosol forcing, lending it increased credibility. Specifically, the IPCC's preferred estimate of aerosol forcing (cooling) has declined over time, 
which leads to a lower preferred ECS estimate in empirical energy balance models. The methodology of Christy and McNider (2017) provides an independent and model-free check on this approach. Also, while climate models with high ECS values can be made to fit the surface warming trend, they have shown demonstrably excess warming elsewhere, especially in the troposphere over the tropics (Fu et al. 2011; McKitrick and Christy 2018). We therefore believe that the LC18 results in Table 2 are more credible than the ones conditioned on the Roe-Baker distribution.

Another if-then statement concerns $\mathrm{CO}_{2}$ fertilization of agriculture. If adding $\mathrm{CO}_{2}$ to the air has no effect on plant growth, then the assumption in DICE and PAGE that the effect is non-existent is appropriate. However, there is overwhelming evidence that $\mathrm{CO}_{2}$ increases do have a beneficial effect on plant growth, so models that fail to take these benefits into account overstate the SCC. Indeed, the initial studies on which the FUND parameterizations were based cautioned against ignoring this line of benefit (Kane et al. 1992; Tsigas et al. 1997). The recent literature on global greening and the response of agricultural crops to enhanced $\mathrm{CO}_{2}$ availability suggests that the productivity boost is likely stronger than that parameterized in FUND. If the effect is $30 \%$ stronger, and if the Lewis and Curry ECS distribution is valid, then the mean social cost of carbon is negative even at discount rates as low as $2.5 \%$ at least through mid-century.

Acknowledgements No funding was received for this work. We thank, without implicating, David Anthoff for advice on the structure of FUND. The views expressed herein are the authors' own and do not necessarily represent those of any organizations with which the authors are affiliated.

Open Access This article is licensed under a Creative Commons Attribution 4.0 International License, which permits use, sharing, adaptation, distribution and reproduction in any medium or format, as long as you give appropriate credit to the original author(s) and the source, provide a link to the Creative Commons licence, and indicate if changes were made. The images or other third party material in this article are included in the article's Creative Commons licence, unless indicated otherwise in a credit line to the material. If material is not included in the article's Creative Commons licence and your intended use is not permitted by statutory regulation or exceeds the permitted use, you will need to obtain permission directly from the copyright holder. To view a copy of this licence, visit http://creativecommons.org/licen ses/by/4.0/.

\section{References}

Aldrin M, Holden M, Guttorp P, Skeie RB, Myhre G, Berntsen TK (2012) Bayesian estimation of climate sensitivity based on a simple climate model fitted to observations of hemispheric temperatures and global ocean heat content. Environmetrics 23:253-271

Andrews T et al (2012) Forcings, feedbacks, and climate sensitivity in the CMIP5 coupled atmosphereocean climate models. Geophys Res Lett. https://doi.org/10.1029/2012GL051607

Anthoff D, Tol RSJ (2013) The uncertainty about the social cost of carbon: a decomposition analysis using FUND. Clim Change 117:515-530. https://doi.org/10.1007/s10584-013-0706-7

Butler EE, Mueller ND, Huybers P (2018) Peculiarly pleasant weather for US maize. Proc Natl Acad Sci. https://doi.org/10.1073/pnas.1808035115

Cai Y, Lontzek TS (2019) The social cost of carbon with economic and climate risks. J Polit Econ. https ://doi.org/10.1086/701890 (in press)

Challinor AJ et al (2014) A meta-analysis of crop yield under climate change and adaptation. Nat Clim Change 4(4):287 
Christy JR, McNider R (2017) Satellite bulk tropospheric temperatures as a metric for climate sensitivity. Asia Pac J Atmos Sci 53:511-518

Cuniff J, Osborne CP, Ripley BS, Charles M, Jones G (2008) Response of wild C4 crop progenitors to subambient $\mathrm{CO}_{2}$ highlights a possible role in the origin of agriculture. Glob Change Biol 14:576-587

Dayaratna K, McKitrick R, Kreutzer D (2017) Empirically-constrained climate sensitivity and the social cost of carbon. Clim Change Econ. https://doi.org/10.1142/S2010007817500063

Deryng D, Elliott J, Folberth C et al (2016) Regional disparities in the beneficial effects of rising $\mathrm{CO}_{2}$ concentrations on crop water productivity. Nat Clim Change. https://doi.org/10.1038/NCLIMATE29 95

Fu Q, Manabe S (2011) Johanson CM (2011) On the warming in the tropical upper troposphere: models versus observations. Geophys Res Lett 38:L15704. https://doi.org/10.1029/2011GL048101

Gao X, Liang S, He B (2018) Detected global agricultural greening from satellite data. Agric For Meteorol. https://doi.org/10.1016/j.agrformet.2019.107652

Gillingham K, Nordhaus W, Anthoff D et al (2018) Modeling uncertainty in integrated assessment of climate change: a multimodel comparison. J Am Assoc Resour Environ Econ 5:4. https://doi. org/10.1086/698910

Hope C (2006) The marginal impact of $\mathrm{CO}_{2}$ from PAGE2002: an integrated assessment model incorporating the IPCC's five reasons for concern. Integrat Assess J 6(1):19-56

Hourdin F, Mauritsen T, Gettelman A et al (2017) The art and science of climate model tuning. Bull Am Meteorol Soc. https://doi.org/10.1175/BAMS-D-15-00135.1

Idso KE, Idso SB (1994) Plant responses to atmospheric $\mathrm{CO}_{2}$ enrichment in the face of environmental constraints: a review of the past 10 years' research. Agric For Meteorol 69:153-203

Intergovernmental Panel on Climate Change (2013) Climate change 2013: the physical science basis. In: Stocker TF, D Qin, G-K Plattner, M Tignor, SK Allen, J Boschung, A Nauels, Y Xia, V Bex, PM Midgley (eds). Cambridge University Press, Cambridge.

Kane S, Reilly J, Tobey J (1992) An empirical study of the economic effects of climate change on world agriculture. Clim Change 21:17-35

Kiehl JT (2007) Twentieth century climate model response and climate sensitivity. Geophys Res Lett 34:L22710. https://doi.org/10.1029/2007GL031383

Kimball BA (2016) Crop responses to elevated $\mathrm{CO}_{2}$ and interactions with $\mathrm{H}_{2} \mathrm{O}, \mathrm{N}$, and temperature. Curr Opin Plant Biol 31:36-43

Lewis N (2013) An objective Bayesian, improved approach for applying optimal fingerprint techniques to estimate climate sensitivity. J Clim 26:7414-7429

Lewis N, Curry JAC (2015) The implications for climate sensitivity of AR5 forcing and heat uptake estimates. Clim Dyn. https://doi.org/10.1007/s00382-014-2342-y

Lewis N, Curry J (2018) The impact of recent forcing and ocean heat uptake data on estimates of climate sensitivity. J Clim. https://doi.org/10.1175/JCLI-D-17-0667.1

Link PM, Tol RSJ (2011) The economic impact of a shutdown of the thermohaline circulation: an application of FUND. Clim Change 102:287-304

Marten AL (2011) Transient temperature response modeling in IAMs: the effects of over simplification on the SCC. Econ E-J 5:2011-2018. https://doi.org/10.5018/economics-ejournal.ja.2011-18

Masters T (2014) Observational estimate of climate sensitivity from changes in the rate of ocean heat uptake and comparison to CMIP5 models. Clim Dyn 42:2173-2181. https://doi.org/10.1007/s0038 2-013-1770-4

McKitrick RR, Christy J (2018) A test of the tropical 200-300 mb warming rate in climate models. Earth Sp Sci. https://doi.org/10.1029/2018EA000401

Munier S, Carrer D, Planque C et al (2018) Satellite leaf area index: global scale analysis of the tendencies per vegetation type over the last 17 years. Remote Sens. https://doi.org/10.3390/rs10030424

Nicholls RJ, Tol RSJ, Vafeidis AT (2008) Global estimates of the impact of a collapse of the West-Antarctic Ice Sheet. Clim Change 91:171-191

Nordhaus W (1993) Optimal greenhouse-gas reductions and tax policy in the "DICE" Model. Am Econ Rev 83(2, Papers and Proceedings):313-317

Olsen R, Sriver R, Goes M et al (2012) A climate sensitivity estimate using bayesian fusion of instrumental observations and an earth system model. Geophys Res Lett 117(D04103):1-11

Otto A, Otto FEL, Allen MR, Boucher O, Church J, Hegerl G, Forster PM, Gillett NP, Gregory J, Johnson GC, Knutti R, Lohmann U, Lewis N, Marotzke J, Stevens B, Myhre G, Shindell D (2013) Energy budget constraints on climate response. Nat Geosci 6:415-416 
Pindyck R (2013) Climate change policy: what do the models tell us? J Econ Lit 51(3):860-872

Ring MJ, Lindner D, Cross EF, Schlesinger ME (2012) Causes of the global warming observed since the 19th century. Atmos Clim Sci 2:401-415

Roe GH, Baker MB (2007) Why is climate sensitivity so unpredictable? Science 318(5850):629-632

Roe GH, Bauman Y (2013) Climate sensitivity: should the climate tail wag the policy dog? Clim Change 2013(117):647-662. https://doi.org/10.1007/s10584-012-0582-6

Sandmo A (1975) Optimal taxation in the presence of externalities. Swed J Econ 77(1):86-98

Skeie RB, Berntsen T, Aldrin M, Holden M, Myhre G (2014) A lower and more constrained estimate of climate sensitivity using updated observations and detailed radiative forcing time series. Earth Syst Dyn 5:139-175. https://doi.org/10.5194/esd-5-139-2014

Tsigas ME, Frisvold GB, Kuhn B (1997) Global climate change and agriculture. In: Hertel T (eds) Global trade analysis: modeling and applications. Cambridge University Press, New York.

Tol RSJ (1997) On the optimal control of carbon dioxide emissions: an application of FUND. Environ Model Assess 2:151-163

Tol RSJ (2017) The structure of the climate debate. Energy Policy 104:431-438

US Office of Management and Budget (2003) Circular A-4 United States Government. https://www.white house.gov/sites/whitehouse.gov/files/omb/circulars/A4/a-4.pdf

US Interagency Working Group on Social Cost of Carbon (IWG) (2010) Social cost of carbon for regulatory impact analysis under executive order 12866. United States Government. https://www.white house.gov/sites/default/files/omb/inforeg/for-agencies/Social-Cost-of-Carbon-for-RIA.pdf.

US Interagency Working Group on Social Cost of Carbon (IWG) (2013) Technical support document: technical update of the social cost of carbon for regulatory impact analysis Under Executive Order 12866. United States Government

Webster M, Jakobovits L, Norton J (2008) Learning about climate change and implications for near-term policy. Clim Change 89:67-85. https://doi.org/10.1007/s10584-008-9406-0

Weyant J (2017) Some contributions of integrated assessment models of global climate change. Rev Environ Econ Policy 11(1, Winter 2017):115-137. https://doi.org/10.1093/reep/rew018

Wouter Botzen WJ, van den Bergh JCJM (2012) How sensitive is Nordhaus to Weitzman? Climate policy in DICE with an alternative damage function. Econ Lett 117:372-374

Wu J, Kronzucker H, Shi W (2018) Dynamic analysis of the impact of free-air $\mathrm{CO}_{2}$ enrichment (FACE) on biomass and $\mathrm{N}$ uptake in two contrasting genotypes of rice. Funct Plant Biol 45:696-704. https:// doi.org/10.1071/FP17278

Zhu C, Xu X, Wang D, Zhu J, Liu G (2015) An indica rice genotype showed a similar yield enhancement to that of hybrid rice under free air carbon dioxide enrichment. Nat Sci Rep. https://doi.org/10.1038/ srep12719

Zhu Z, Piao S, Myneni R et al (2016) Greening of the earth and its drivers. Nat Clim Change. https://doi. org/10.1038/NCLIMATE3004

Publisher's Note Springer Nature remains neutral with regard to jurisdictional claims in published maps and institutional affiliations. 